\title{
CD44+/CD24- MARKERS OF CANCER STEM CELLS IN PATIENTS WITH BREAST CANCER OF DIFFERENT MOLECULAR SUBTYPES
}

\author{
S.V. Chekhun ${ }^{1,}$, T.V.Zadvorny ${ }^{1}$, Yu.O. Tymovska ${ }^{2}$, M.F. Anikusko', O.E. Novak', L.Z. Polishchuk ${ }^{1}$ \\ ${ }^{I}$ R.E. Kavetsky Institute of Experimental Pathology, Oncology and Radiobiology, NAS of Ukraine, \\ Kyiv 03022, Ukraine \\ ${ }^{2}$ Kyiv City Clinical Oncological Center, Kyiv 03022, Ukraine
}

\begin{abstract}
Aim: To determine frequency of tumors with immunohistochemical markers of cancer stem cells (CSC) CD44+/CD24- in patients with breast cancer (BC) of different molecular subtype and to evaluate their prognostic value. Object: Surgical material of 132 patients with BC stage I-II, age from 23 to 75 years, mean age $-50.2 \pm 3.1$ years was studied. Methods: Clinical, immunohistochemical (expression CD44+/CD24-), morphological, statistical. Results: BC is characterized by heterogeneity of molecular subtypes and expression of markers (CD44+/CD24-). Immunohistochemical study of expression of CSC markers in surgical material has detected their expression in 34 (25.4\%) patients with BC of different molecular subtypes. The highest frequency of cells with expression of CSC marker was observed in patients with basal molecular subtype (44.8\% patients). Most of BC patients with phenotype CD44+/CD24 had stage I of tumor process (34.3\%). Statistical processing of data has showen that Yule colligation coefficient equaled $0.28(\mathrm{p}>0.05)$ that argues poor correlation between stage of tumor process and number of tumors with positive expression of CSC markers. Statistical processing of data has showen high correlation between presence of cells with expression of CSC markers and metastases of BC in regional lymph nodes (Yule colligation coefficient equals 0.943; p $<0.5$ ). Difference in overall survival of patients with BC of basal molecular subtype depending on expression of CSC CD44+/CD24- markers was detected. Survival of patients with basal BC was reliably higher at lack in tumors of cells with CSC markers CD44+/CD24- and, correspondingly, lower at presence of such cells $(\mathrm{p}<0.05)$. In patients with BC of luminal (A and B), HER-2-positive subtypes, significant change in survival of patients depending on expression of CSC markers was not determined (p $>0.05)$. Conclusion: Significance of tumor cells with markers CD44+/CD24- within the limits of molecular subtype of BC may be additional criterion for advanced biological characteristic of $\mathrm{BC}$, and in patients with $\mathrm{BC}$ of basal molecular subtype - for predictive evaluation of individual potential of tumor to aggressive clinical course.
\end{abstract}

Key Words: breast cancer, cancer stem cells, CD44+/CD24-, molecular subtype.

Breast cancer $(B C)$ is one of the most widespread forms of female cancer pathology in many countries of the world. Dangerous situation concerning BC is observed in Ukraine as well: according to updated information of National Cancer Register of Ukraine (2012) BC morbidity and mortality (raw indices) are respectively 72.5 and 32.2 per 100000 of female population. Only $13.3 \%$ patients has received surgical treatment alone, while combined or complex treatment $68.5 \%$ [1] that evidences that the significant number of patients had advanced stages of BC. Treatment results, being not always satisfactory due to tumors' chemo- and radioresistances and significant variability of $B C$ clinical course [2-6], serve the basis for more pronounced study of $\mathrm{BC}$ biology from positions of its origin, growth and metastasis.

Intense molecular-biological studies have determined that $\mathrm{BC}$ is complicated multi-stage process of accumulation of structural and functional effects of genes, which are associated with proliferation, neoangiogenesis, intercellular adhesion disturbances, peculiarities of microenvironment of tumor cells and their clonal evolution. The main result of these studies was the identification of $\mathrm{BC}$ as heterogeneous disease with

Submitted: January 05, 2015

*Corresponding: E-mail: chekhun@yahoo.com Abbreviations used: BC - breast cancer; CSC - cancer stem cells; ER - estrogen receptors; HER2/neu - human epidermal growth factor type 2; PR - progesterone receptors. different properties of growth and metastasis [7, 8]. This is confirmed by identification of different BC molecular subtypes depending on expression of estrogen receptors (ER), progesterone receptors (PR) and human epidermal growth factor type 2 (HER2/neu). Basing on this, the following BC subtypes were determined, namely: luminal A, luminal B, basal or triplenegative, HER2/neu-positive [9-12]. Mammologists are guided by these biological subtypes while treatment process and evaluation of disease prognosis.

Despite widespread use of such classification in clinical practice, it is not always possible to predict precisely the clinical course of disease and tumor "response" to the treatment. It is due to the fact that $\mathrm{BC}$ of one histological type or even of one molecular subtype is characterized by different proliferative potential of tumor cells, adhesion disturbances, peculiarities of tumor microenvironment, which altogether determine not only intercellular, but also intracellular biological heterogeneity [13-15]. Literature data confirm the dependence of unfavorable BC clinical course and prognosis from tumor biological heterogeneity, genetic and proteomic changes in tumor cells [16-18].

In this aspect, cancer stem cells (CSC) attract attention. According to the conception of CSC significance for tumor occurrence and growth, such cells possess specific features. Like normal stem cells, they have capability to grow, can self-renew and differentiate into various types of cells. Their specific feature is: while CSC division one of the daughter cells preserves properties 
of parent cell, while cells proliferation is associated with CD44+/CD24- phenotype [19-21]. Cells with such phenotype are called tumorogenic or tumor-initiating cells due to the features of their proliferative potential. Studies on CSC have determined that biological and molecular heterogeneity of $\mathrm{BC}$ depends on the amount of such cells [22], their microenvironment and expression of certain cytokines [23]. Biological properties of these cells were studied on experimental cells lines in vitro [24]. Earlier in our studies on CSC in cell lines of BC (T47D, MCF-7, MDA-MB 231, MDA-MB 468) we have determined some regularities of CSC markers expression depending on their molecular phenotype [25].

Thus, in modern literature, both the significance of $\mathrm{BC}$ molecular phenotypes for characterization of $B C$ heterogeneity and the hypothesis of intratumoral heterogeneity formation, in which CSC may play significant role, are actively discussed. But CSC association with clinical features of $\mathrm{BC}$ of different histological types, with metastasis and patients survival remains unclear. For this reason, the study of BC heterogeneity and cellular peculiarities of tumors using immunohistochemical markers of CSC is relevant problem, which solution will promote extension of knowledge on biology of tumor growth in mammary gland and improve patients' treatment.

Taking into account above-stated, the aim of this study was to determine the prevalence of tumors with immunohistochemical markers of cancer stem cell CD44+/CD24- in patients with BC of different molecular subtype and evaluate their prognostic significance.

\section{MATERIALS AND METHODS}

Our studies are based on retrospective analysis of results of examination, treatment and survival of 132 BC patients with I-II stages, who received special treatment in Kyiv City Clinical Cancer Center during 2005-2007. The samples of surgical material of BC were studied. These samples were stored in clinical database of the Department of Antitumor Therapy Mechanisms of R.E. Kavetsky Institute of Experimental Pathology, Oncology and Radiobiology, NAS of Ukraine. The tumor stage was determined according to the International Tumor Classification (TNM, Edition 6, 2002). Histological type of tumors was verified on histological sections of tumors' paraffin blocks (staining with hematoxylin and eosin) according with the WHO International Histological Classification (2006). Depending on clinical indications, patients underwent organ-saving surgeries or radical Madden mastectomies, and adjuvant polychemotherapy (CAF or AC schemes with 21 day interval, number of courses varied from 4 to 6 ), according with the approved in Ukraine Standards of BC Patients' Treatment. Postoperative radiation therapy was performed on postoperative scar, axillary, parasternal and supraclavicular regions; the single focal dose was $2 \mathrm{~Gy}$, and the total focal dose - 40 Gy.

For evaluation of BC molecular subtype we performed the immunohistochemical studies of expres- sion of three molecular markers that are widely used nowadays for immunohistochemical BC diagnosis: ER, PR, Her2/neu. We used histological sections (4 micron thickness) of paraffin blocks. The following monoclonal antibodies were used: antiER - clone 1D5, antiPRclone PgR636, antiHER/2neu - clone c-erbB-2 (Dako Cytomation, Denmark). The number of cells with positive markers expression were determined taking into account the level of immunohistochemical reaction: "+++" - strong, "++" - moderate, "+" - low, "0" lack of expression. On the parallel paraffin sections the immunohistochemical study of CD24 and CD44 expression in tumor cells were carried out. As primary antibodies, monoclonal antibodies specific to CD24 (clone SN3b, ThermoScientific, USA) and to CD44 (CD44/ HCAM, clone 156-3C11, Diagnostic BioSystems, USA) were used in dilutions according to the manufacturer guideline. The number of immunopositive tumor cells more than $10 \%$ was taken as positive marker expression. For visualization of the results of all immunohistochemical reactions EnVision system (Dako LSAB2 system, Denmark) was used according to the manufacturer guidelines; histological sections were stained with Mayer's hematoxylin. Results of immunohistochemical reactions were analyzed using optic microscope XSP137-BP, JNOEC, magnification $\times 200-400$.

Statistic processing of the obtained results was carried out using methods of variation statistics by program Statistica v. 6.0. For evaluation of correlation between expression of studied markers and clinical and pathological features of $\mathrm{BC}$, we used the Pearson coefficient of mutual conjugation (c), Yule coefficient of association, Cox regression analysis. Evaluation of survival was carried out using Kaplan - Meier method starting from the date of treatment beginning, using log-rank test. Differences were considered significant at $p \leqslant 0.05$.

\section{RESULTS AND DISCUSSION}

General clinical description of 132 BC patients with stage I-II is presented in the Table 1 . The number of BC patients with stage I was $26.5 \%$, with stage II $73.5 \%$. Patients' age was varied from 23 to 75 years, mean age was $50.2 \pm 3.1$ years. The majority of patients were in age interval 41-70 (Fig. 1, Table 1).

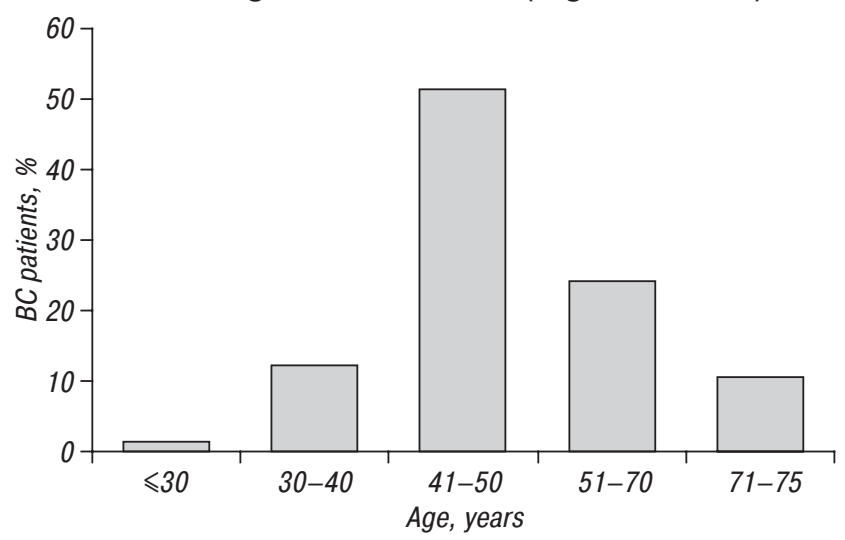

Fig. 1. Distribution of BC patients with stage I-II by age 
Table 1. General clinical description of BC patients with stage I-II

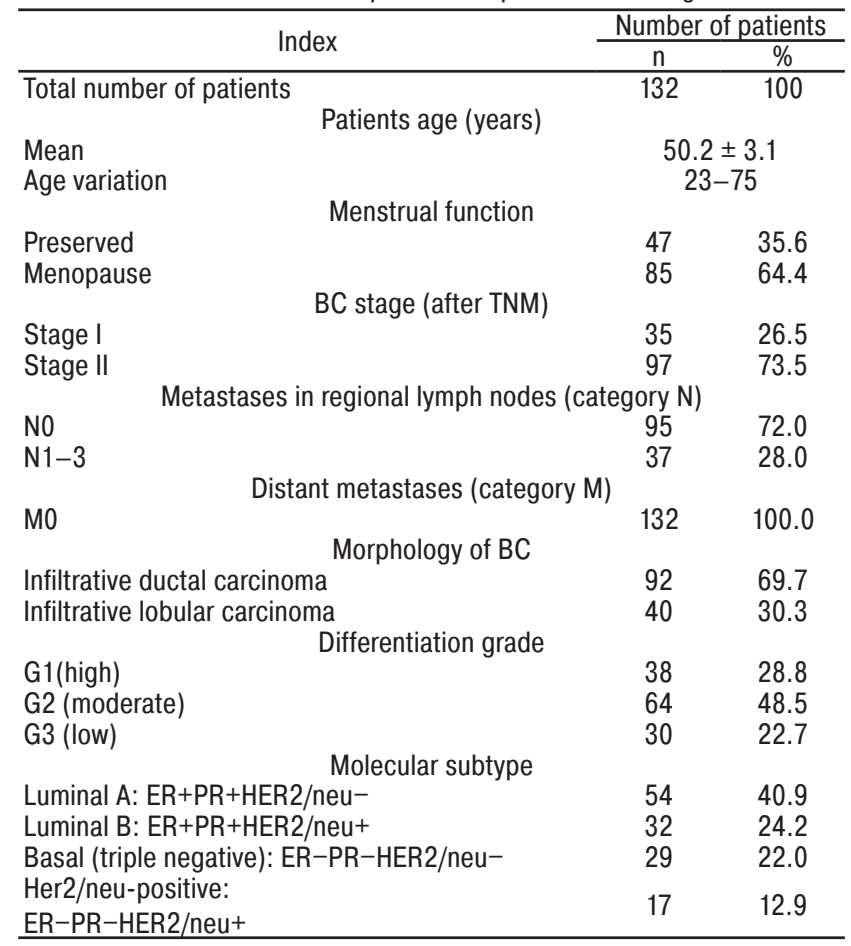

According to the results of complex examination of patients (X-ray, ultrasound, etc.), metastases in regional lymph nodes (N1-3) were detected in $28.0 \%$ cases, distant metastases were not detected. Morphological study has determined infiltrating ductal BC $(69.7 \%)$ more often, than lobular BC (30.3\%). More often moderate differentiation of $\mathrm{BC}(48.5 \%)$ as compared with high and low differentiation (28.8 and $22.7 \%$, correspondingly) was observed.

Analysis of the results of immunohistochemical study of ER, PR and Her2/neu expressions evidenced luminal A subtype in 40.9\% cases, luminal B subtype in $24.2 \%$, basal subtype - in $22.0 \%$, and Her2/neupositive subtype - in $12.9 \%$ cases (Table 1 ).

More detailed clinical and pathomorphological description of tumor process in BC patients depending on molecular subtype of BC is shown in Table 2. Distribution of patients by mean age has not detected significant difference $(p>0.05)$. Most patients with luminal A, basal and Her2/neu-positive molecular subtypes (70.4-72.4\%) were menopausal, while among patients with luminal B subtype such patients were 43.8\%. In all molecular subtypes, mostly stage II was diagnosed, especially in patients with luminal A (83.4\%) and basal (82.8\%) subtypes, while in patients with Her2/neu-positive and luminal B subtypes, stage II was in 53.0 i $59.4 \%$ cases, respectively. Frequency of metastasis in regional lymph nodes was significantly lower in $\mathrm{BC}$ patients with both luminal subtypes.

In patients with basal and Her2/neu-positive subtypes the number of patients without metastases and with metastases was almost the same: basal subtype (51.7 and 48.3\%, respectively) and Her2/neu-positive subtype (52.9 and $47.1 \%$, respectively). Irrespectively of tumor molecular subtype, ductal carcinoma prevailed in all patients, varying from $55.5 \%$ in luminal A subtype to $79.3 \%$ in basal (triple negative) subtype.
Table 2. Distribution of BC patients with different molecular subtypes according to clinical data

\begin{tabular}{|c|c|c|c|c|c|c|c|c|}
\hline \multirow{3}{*}{ Indices } & \multicolumn{8}{|c|}{ Molecular subtype } \\
\hline & \multicolumn{2}{|c|}{$\begin{array}{c}\text { Luminal A } \\
n=54 \\
(100 \%)\end{array}$} & \multicolumn{2}{|c|}{$\begin{array}{l}\text { Luminal B } \\
n=32 \\
(100 \%)\end{array}$} & \multicolumn{2}{|c|}{$\begin{array}{c}\text { Basal } \\
n=29 \\
(100 \%)\end{array}$} & \multicolumn{2}{|c|}{$\begin{array}{c}\text { Her2/neu- } \\
\text { positive } \\
n=17 \\
(100 \%)\end{array}$} \\
\hline & $\frac{\mathrm{n}}{513}$ & $\begin{array}{c}\% \\
47\end{array}$ & $\frac{n}{468}$ & $\begin{array}{c}\% \\
25\end{array}$ & $\frac{n}{481}$ & $\begin{array}{c}\% \\
18\end{array}$ & $\frac{1}{50}$ & $\%$ \\
\hline Reprc & 16 & 29.6 & 18 & 56.2 & 8 & 27.6 & 5 & 29.4 \\
\hline $\begin{array}{l}\text { Menopausal period, } n=85 \\
\text { Stage }\end{array}$ & 38 & 70.4 & 14 & 43.8 & 21 & 72.4 & 12 & 70.6 \\
\hline Stage I, $n=35$ & 9 & 16.6 & 13 & 40.6 & 5 & 17.2 & 8 & 47.0 \\
\hline $\begin{array}{l}=97 \\
\text { es in lymph nodes }\end{array}$ & 45 & 83.4 & 19 & 59.4 & 24 & 82.8 & 9 & 53.0 \\
\hline No me & 45 & 83.3 & 26 & 81.2 & 15 & 51.7 & 9 & 52.9 \\
\hline $\begin{array}{l}\text { Metastases in regional } \\
\text { lymph nodes, N1-3, } n=37 \\
\text { Histological subtypes }\end{array}$ & 9 & 16.7 & 6 & 18.8 & 14 & 48.3 & 8 & 47.1 \\
\hline $\begin{array}{l}\text { Infiltrative ductal carcino- } \\
\mathrm{ma}, \mathrm{n}=92\end{array}$ & 30 & 55.5 & 25 & 78.1 & 23 & 79.3 & 14 & 82.3 \\
\hline $\begin{array}{l}\text { Infiltrative lobular carcino- } \\
\text { ma, } n=40 \\
\text { Differentiation grade }\end{array}$ & 24 & 44.5 & 7 & 11.9 & 6 & 20.7 & 3 & 17.7 \\
\hline & 18 & 33.3 & 10 & 31.3 & 7 & 24.1 & 3 & 17.6 \\
\hline Mode & 22 & 40.7 & 9 & 28.1 & 21 & 72.4 & 12 & 70.6 \\
\hline Low, $n=30$ & 14 & 26.0 & 13 & 40.6 & 1 & 3.5 & 2 & 11.8 \\
\hline
\end{tabular}

The significant priority of moderate grade of tumor differentiation was determined in luminal A $(40.7 \%)$, basal (72.4\%) and Her2/neu-positive (70.6\%) subtypes, and only in luminal B subtype the low grade of tumor differentiation (40.6\%) prevailed. These data evidenced the intertumoral heterogeneity of $\mathrm{BC}$ both by clinical indices and by pathomorphological tumor features.

Immunohistochemical study of CSC markers expression in surgical material detected their expression in 34 (25.4\%) BC patients, who had different molecular subtypes. Distribution of this marker expression within each molecular subtype (Table 3) showed that frequency of expression varied: the highest number of tumors with of CSC markers expression was among the patients with luminal $B$ and basal subtypes (28.1 and $44.8 \%$, respectively), while in patients with luminal $\mathrm{A}$ and Her2/neu-positive subtypes it was lower (16.6 and $17.6 \%$, respectively). The highest frequency of cells with CSC marker expression was revealed in $\mathrm{BC}$ patients with basal molecular subtype. The prevalence of cells with CSC markers depending on cells' molecular phenotype was confirmed by Pearson coefficient mutual conjugation ( $c=0.54)$. This indicates the existing of moderate correlation of frequency of cells with CSC markers with tumor molecular subtype $(p<0.05)$.

Table 3. Prevalence of tumors with CSC markers expression in BC patients with different molecular subtypes

\begin{tabular}{|c|c|c|}
\hline \multirow[t]{2}{*}{ Molecular subtype of BC } & \multicolumn{2}{|c|}{$\begin{array}{c}\text { BC patients with ex- } \\
\text { pression of CSC } \\
\text { marker } \\
\text { CD44+/CD24- }\end{array}$} \\
\hline & $n$ & $\%$ \\
\hline Luminal A: ER+PR+Her2/neu-, $n=54(100 \%)$ & 9 & 16.6 \\
\hline Luminal B: ER+PR+Her2/neu+, $n=32(100 \%)$ & 9 & 28.1 \\
\hline Basal: ER-PR-Her2/neu-, n = 29 (100\%) & 13 & 44.8 \\
\hline Her2/neu-positive: ER-PR-Her2/neu+, $n=17(100 \%)$ & 3 & 17.6 \\
\hline
\end{tabular}

Among criteria, which have essential clinical significance for prognosis evaluation and conduction adequate therapy of $\mathrm{BC}$ patients, the stage of tumor process is crucial. 
The majority of BC patients with CD44+/CD24phenotype had BC I stage (34.3\%). Statistic analysis showed that Yule association coefficient was 0.28 ( $p>0.05)$, which underlines poor correlation between tumor process stage and number of tumors with positive CSC markers expression (Table 4).

Table 4. Distribution of tumors with CSC marker CD44+/CD24- expression in BC patients with I-II stage

\begin{tabular}{ccc}
\hline Characteristic & \multicolumn{2}{c}{ Tumors with expression of CSC marker CD44+/CD24- } \\
\cline { 2 - 3 } of patients & $\mathrm{n}$ & $\%$ \\
\hline Stage I, $\mathrm{n}=35$ & 12 & 34.3 \\
Stage II, $\mathrm{n}=97$ & 22 & 22.7 \\
\hline
\end{tabular}

Taking into account literature data on possible impact of CSC expression in primary tumor and higher proliferative, invasive and metastatic potential of tumors, it was of certain interest to study the correlation between frequency of tumors with CD44+/ CD24- markers in patients with or without regional metastases. Among total number of patients without metastases the CD44+/CD24- markers was observed in $7(7.4 \%)$ cases, while among those with metastases such phenotype was detected more often - in 27 (72.9\%) cases (Table 5). Statistic analysis showed high correlation between the presence of cells with CSC markers expression and BC metastases in regional lymph nodes (Yule association coefficient: 0.943; $p<0.05)$.

Table 5. Distribution of tumors with CSC marker CD44+/CD24- expression in $\mathrm{BC}$ patients without metastases and with regional metastases

\begin{tabular}{lcc}
\hline \multicolumn{1}{c}{ Characteristic of patients } & \multicolumn{2}{c}{$\begin{array}{c}\text { Tumors with expression of CSC } \\
\text { marker CD44+/CD24- }\end{array}$} \\
\cline { 2 - 4 } & $\mathrm{n}$ & $\%$ \\
\hline No metastases, (N0), $\mathrm{n}=95(100 \%)$ & 7 & 7.4 \\
Metastases in regional lymph nodes & 27 & $72.9^{*}$ \\
(N1-3), $\mathrm{n}=37(100 \%)$ & 27 &
\end{tabular}

Notes: ${ }^{*} \mathrm{p}<0.05$ compared to group of patients without metastasis.

In clinical studies the significance of BC differentiation grade for clinical course of disease was evidenced. For this reason, further analysis of obtained results of immunohistochemical study was devoted to comparison of CD44+/CD24- expression in BC with different tumor differentiation (Table 6). The analysis of distribution of tumors with phenotype CD44+/ CD24- showed that in group of patients with high and moderate tumor differentiation the amount of such tumors was lower ( 18.4 and $25.0 \%$, respectively) than in patients with low differentiation (36.7\%). Statistic processing detected poor correlation between tumor differentiation grade and expression of CSC markers (Pearson coefficient $\mathrm{c}=0.3 ; \mathrm{p}>0.05$ ).

Table 6. Distribution of tumors with CSC marker CD44+/CD24- expression in $\mathrm{BC}$ of different differentiation grade

\begin{tabular}{lcc}
\hline \multirow{2}{*}{$B C$ differentiation grade } & Number of tumors with phenotype CD44+/CD24- \\
\cline { 2 - 3 } & $\mathrm{n}$ & $\%$ \\
\hline High, $\mathrm{n}=38(100 \%)$ & 7 & 18.4 \\
Moderate, $\mathrm{n}=64(100 \%)$ & 16 & 25.0 \\
Low, $\mathrm{n}=30(100 \%)$ & 11 & 36.7 \\
\hline
\end{tabular}

Taking into account obtained results, which are characterized by variability of molecular subtypes in $\mathrm{BC}$ patients and CSC markers expression, it was important to evaluate significance of the latter as criteria of patients' overall survival. Fig. 2 shows curves of overall survival of $\mathrm{BC}$ patients with different molecular subtypes depending on presence or lack of tumor cells with CSC markers. As it could be seen from presented data, survival of patients with basal BC was significantly higher at lack of the cells with phenotype CD44+/CD24-in tumors and, correspondingly, lower at presence of such cells $(p<0.05)$. In patients with $B C$ of luminal ( $A$ and $B$ ) and HER-2-positive subtypes, significant changes in survival depending on CSC markers expression were not found ( $p>0.05)$.

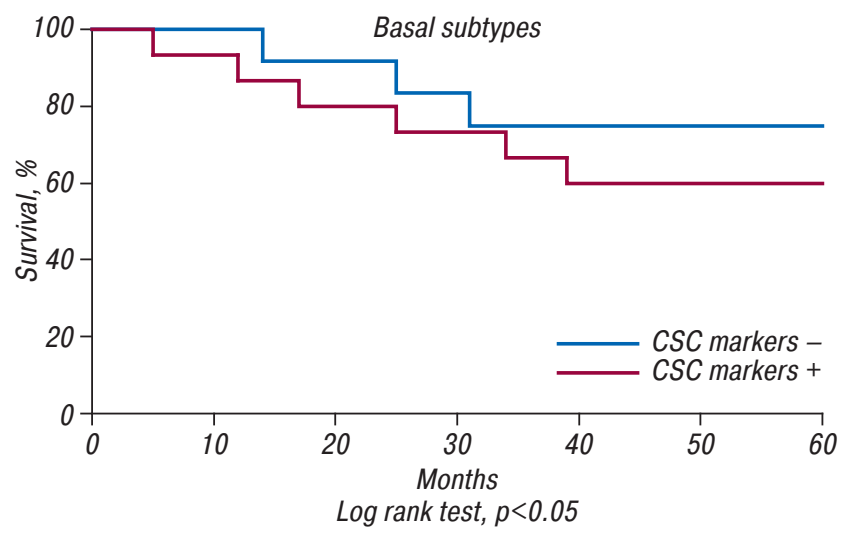

Fig. 2. Overall survival of $B C$ patients with different molecular subtypes depending on presence or lack of SCS markers in tumor cells

In order to determine the significance of using CSC markers CD44+/CD24- in clinical practice, Cox regression analysis was carried out. Its results suggest the possibility of using this index (phenotype of CSC CD44+/CD24-) as marker for prediction of individual prognosis for patients with basal BC (Table 7).

Table 7. Results of Cox regression analysis

\begin{tabular}{clcc}
\hline Marker & Molecular subtype & $\beta$ & $\mathrm{p}$ \\
\hline CD44+/CD24- & Luminal A & -0.11 & $>0.05$ \\
& Luminal B & -0.21 & $>0.05$ \\
& HER-2/neu-positive & 0.17 & $>0.05$ \\
& Basal (triple negative) & 0.57 & $<0.05$ \\
\hline
\end{tabular}

Thus, obtained results show that $\mathrm{BC}$ is characterized by heterogeneity by not only tumors' morphology, but also by molecular subtypes and by CSC markers expression (CD44+/CD24-). Genetic heterogeneity of invasive forms of $\mathrm{BC}$ is reflected in wide range of histological types, various tumor differentiation grade and variability of disease clinical course. As it is known, the luminal subtype $A$ is referred to the low-aggressive tumors with favorable prognosis; on the contrary, the luminal $B$ subtype is characterized by aggressiveness and worse prognosis. Other subtypes - HER2-positive and triple negative (basal subtype) - are referred to the tumors with worse prognosis of survival, though in the first one the HER2/neu expression occurs, while in the latter no changes of this cancer oncogene were detected. At the same time, exactly the basal subtype is characterized by the worst patients' survival rates. It can be suggested that in aggressive course of $\mathrm{BC}$ of basal subtype the particular role is played by cells with CSC phenotype CD44+/CD24-. In the relationship "CSC and cancer" many unsolved questions remain. For this reason, CSC origin, their evolution, role of such molecular markers as CD44 and 
CD24 in different stages of tumor genesis are under wide discussion [12, 26-28].

Population of CSC is not large as compared with general population of cells in tumor, but it can seriously impact biological properties of BC. The following literature data confirm this. In BC patients the connection between expression of cells with CD44+/ CD24- and aggressive clinical course and metastasis was determined [29, 30]. The disseminated cells with CD44+/CD24- markers appear already at the early stage of tumor genesis in mammary gland [31]. The correlation between CSC CD44+/CD24- and the epidermal growth factor receptor (EGFR) in invasive variant of ductal carcinoma, which can favor higher proliferation of tumor cells, was found. Increase of proportion of cells with phenotype CD44+/CD24-/low is significant for manifestations of $\mathrm{BC}$ aggressiveness and increased metastasis risk [32]. There are signs that tumor cells with mentioned phenotype play certain role not only in activation of metastasis, but also in formation of resistance to cytostatic drugs [33]. Subpopulations of cells with CSC phenotype are relatively more radioresistant, so it can be associated with development of relapses after radiotherapy [34]. One more important fact is the lack of correlation between cells with phenotype CD44+/CD24- and response to hormone therapy in patients with receptor-positive forms of BC [35].

At the same time, it was determined that fraction of tumor cells CD44+/CD24-/low is quite flexible and depends on many factors, including signals of microenvironment. For example, under hypoxia of tumors in cancer patients with CSC phenotype CD44+/CD24-/ low, the prognosis is significantly worse. Some authors noticed the changes of CD44+ and CD24- expressions in metastases as compared with primary tumor [36]. We also confirmed this fact in immunohistochemical study of CD44s expression in primary tumors and implanted metastases of serous ovary cancer. It was found that changes of this marker expression in implanted metastases had different tendencies: only in $26.7 \%$ of patients CD44s expression did not change, while the number of CD44s-positive cells increased in $46.6 \%$ cases and in $26.7 \%$ cases decreased [37]. These changes underline the individual nature of intercellular adhesion molecule expression in implanted metastases that can be the evidence of clonal nature of metastasis or changes on the level of tumor-host (metabolic, hormonal etc.). If we take into account the study of M. Shipitsin et al. [38], the relations between cells with different phenotype in tumor population are depended on their differentiation response to the activation of TGF- $\beta$ signal pathway.

Obtained results demonstrate multiple functions of CSC and their connection with unequal manifestations of $\mathrm{BC}$ aggressiveness of different molecular subtypes. Undoubtedly, the role of CSC in BC, as well as in tumors of other genesis, their association with patients' hormonal status, peculiarities of microenvironment and other important functions of these cells are not fully identified. At the same time, despite existing disputable issues, CSC may be considered as very interesting for active future studies of the role of these cells at different stages of tumor genesis. It is important for understanding the molecular mechanisms of formation of different molecular BC subtypes, as well as for study of possibilities of using CSC as individual markers of tumors' malignancy and disease clinical course, as well as for clarified personalized treatment.

\section{CONCLUSION}

Within the luminal $A$ and $B$, triple negative and HER2positive molecular phenotypes of $\mathrm{BC}$ the differences in frequency of cells with CSC markers CD44+/CD24were determined. The highest amount of such cells was observed in $\mathrm{BC}$ patients with triple negative (basal) subtype that can be the cause of its aggressive clinical course. Correlation between expression of such cells and presence of metastases in regional lymph nodes was determined. Difference in overall survival of patients with $\mathrm{BC}$ of basal and molecular subtype depending on expression in tumor cells of markers of stem cancer cells CD44+/CD24- was detected.

Detection of tumor cells with markers CD44+/ CD24- within BC molecular subtypes may be additional criterion for the advanced biological characteristic of $\mathrm{BC}$, and in $\mathrm{BC}$ patients with basal molecular subtype - for predictive evaluation of individual potential of tumors to aggressive clinical course.

\section{REFERENCES}

1. Cancer in Ukraine, 2012-2013. Bul Nat Cancer Register of Ukraine. K, 2014: p. 44 (in Ukrainian).

2. Bondar GV, Sedakov IE, Balashova OI, Khomenko AV. Assessment of pathomorphological changes and survival at selective intra-arterial polychemotherapy of locally disseminated breast cancer. Morphologia 2011; 5: 13-23 (in Russian).

3. Shchepotin IB, Smolanka II, Sklyar SYu, et al. Breast cancer. Modern aspects of surgical treatment (by data of National Cancer Institute). Klin Onkol 2013; (1 (9)): 38-43 (in Ukrainian).

4. Smolanka II, Sklyar SYu. Ways of increase of effectiveness of complex treatment of patients with breast cancer. Kyiv: Drukar, 2007. 207 p. (in Ukrainian).

5. Smolanka II, Sklyar SYu, Ivankova OM, et al. Effectiveness of neoadjuvant polychemotherapy in breast cancer patients. Treatment pathomorphism. Klin Onkol 2013; (2 (10)): 1-6 (in Ukrainian).

6. Higgins MJ, Baselga J. Targeted therapies for breast cancer. J Clin Invest 2011; 121: 3797-803.

7. Marusyk A, Polyak K. Tumor heterogeneity: causes and consequences. Biochim Biophys Acta 2010; 1805: 105-17.

8. Bertos NR, Park M. Breast cancer - one term, many entities? J Clin Invest 2011; 121: 3789-96.

9. Sorlie T, Perou CM, Tibshirani R, et al. Gene expression patterns of breast carcinomas distinguish tumor subclasses with clinical implications. Proc NatlAcad Sci U S A 2001;98: 10869-74.

10. Perou CM. Molecular stratification of triple-negative breast cancers. Oncologist 2010; 15: 39-48.

11. Prat A, Parker JS, Karginova O, et al. Phenotypic and molecular characterization of the claudin-low intrinsic subtype of breast cancer. Breast Cancer Res 2010; 12: R68. 
12. Bertucci F, Finetti $P$, Cervera N, et al. How different are luminal A and basal breast cancers? Int J Cancer 2009; 124: $1338-48$.

13. Hernandez L, Wilkerson PM, Lambros MB, et al. Genomic and mutational profiling of ductal carcinomas in situ and matched adjacent invasive breast cancers reveals intratumour genetic heterogeneity and clonal selection. J Pathol 2012; 227: 42-52.

14. Gerlinger M, Rowan AJ, Horswell S, et al. Intratumor heterogeneity and branched evolution revealed by multiregion sequencing. N Engl J Med 2012; 366: 883-92.

15. Martelotto LG, Ng CKY, Piscuoglio S, et al. Breast cancer intra-tumor heterogeneity. Breast Cancer Res 2014; 16: 210 doi: $10.1186 /$ bcr3658.

16. Polyak K. Heterogeneity in breast cancer. J Clin Invest 2011; 121: 3786-8.

17. Zavyalova MV, Denisov EV, Tashireva LA, et al. Phenotypic drift as a cause for intratumoral morphological heterogeneity of invasive ductal breast carcinoma not otherwise specified. Bio Res Open Access 2013; 2: 148-54.

18. Gottlieb B, Alvarado $C$, Wang $C$, et al. Making sense of intratumor genetic heterogeneity: altered frequency of androgen receptor CAG repeat length variants in breast cancer tissues. Human Mutation 2013; 34: 610-8.

19. Al-Hajj M, Becker MW, Wicha M. Therapeutic implication of cancer stem cells. Curr Opin Genet Dev 2004; 14: 43-7.

20. Jordan CT, Guzman ML, Noble M. Cancer stem cells. N Engl J Med 2006; 355: 1253-61.

21. Guo W, Lasky JL, Wu H. Cancer stem cells. Pediatric Res 2006; 59: 59R-64R.

22. Pece S, Tosoni D, Confalonieri S, et al. Biological and molecular heterogeneity of breast cancers correlates with their cancer stem cell content. Cell 2009; 140: 62-73.

23. Korkaya H, Liu S, Wicha MS. Breast cancer stem cells, cytokine networks, and the tumor microenvironment. J Clin Invest 2011; 121: 3804-9.

24. Guttilla IK, Phoenix KN, Hong X, et al. Prolonged mammosphere culture of MCF-7 cells induces an EMT and repression of the estrogen receptor by microRNAs. Breast Cancer Res Treat 2012; 132: 75-85.

25. Chekhun SV, Lukyanova NY, Shvets YV, et al. Significance of ferritin expression in formation of malignant phenotype of human breast cancer cells. Exp Oncol 2014; 36: $179-83$.

26. Kaur S, Singh G, Kaur K. Cancer stem cells: An insight and future perspective. J Cancer Res Ther 2014; 10: 846-52.

27. Nguyen LV, Vanner R, Dirks $P$, et al. Cancer stem cells: an evolving concept. Nat Rev Cancer 2012; 12: 133-43.

28. Kreso A, Dick JE. Evolution of the cancer stem cell model. Cell Stem Cell 2014; 14: 275-91.

29. Kim HJ, Kim MJ, Ahn SH, et al. Different prognostic significance of CD24 and CD44 expression in breast cancer according to hormone receptor status. Breast 2011; 20: 78-85.

30. Zheng Z, Shao N, Weng $H$, et al. Correlation between epidermal growth factor receptor and tumor stem cell markers CD44/CD24 and their relationship with prognosis in breast invasive ductal carcinoma. Med Oncol 2015; 32: 275.

31. Balic M, Lin H, Young L, et al. Most early disseminated cancer cells detected in bone marrow of breast cancer patients have a putative breast cancer stem cell phenotype. Clin Cancer Res 2006; 12: 5615.

32. Li W, Liu F, Lei T, et al. The clinicopathological significance of CD44+/CD24-/low and CD24+ tumor cells in invasive micropapillary carcinoma of the breast. Pathol Res Pract 2010; 206: 828-34.

33. Gudadze M, Kankava K, Mariamidze A, et al. Distribution of cancer stem cells in ductal invasive carcinoma of breast (review). Georgian Med News 2013; 222: 44-50.

34. Phillips TM, McBride WH, Pajonk F. The response of CD24(-/low)/CD44+ breast cancer-initiating cells to radiation. J Natl Cancer Inst 2006; 98: 1777-85.

35. Hashimoto K, Shimizu C, Tsuda $\mathrm{H}$, et al. Immunohistochemical detection of breast cancer stem cells in hormone receptor-positive breast cancer and their role in response to endocrine therapy and clinical outcome. Oncology 2012; 82: 168-74.

36. Oliveira-Costa JP, Zanetti JS, Silveira GG. Differential expression of HIF-1 $\alpha$ in CD44+CD24-/low breast ductal carcinomas. Diagn Pathol 2011; 8: 73.

37. Ryabtseva OD, Antipova SV, Lukyanova NYu, et al. Individual prognosis of serous ovarian cancer survival patients based on adhesion and proliferation of tumor cells. Oncology 2014; 16: 28-32.

38. Shipitsin M, Lauren L, Campbell LL, et al. Molecular definition of breast tumor heterogeneity. Cancer Cell 2007; 11: $259-73$. 